\title{
Melatonin regulates delayed embryonic development in the short-nosed fruit bat, Cynopterus sphinx
}

\author{
Arnab Banerjee, K J Meenakumari, S Udin ${ }^{1}$ and A Krishna \\ Department of Zoology, Banaras Hindu University, Varanasi 221 005, Uttar Pradesh, India and ${ }^{1}$ Neuroscience \\ Program, Department of Physiology and Biophysics, State University of New York at Buffalo, Buffalo,
}

New York 14214, USA

Correspondence should be addressed to A Krishna; Email: akrishna_ak@yahoo.co.in

\begin{abstract}
The aim of the present study was to evaluate the seasonal variation in serum melatonin levels and their relationship to the changes in the serum progesterone level, ovarian steroidogenesis, and embryonic development during two successive pregnancies of $C y n o p t e r u s$ sphinx. Circulating melatonin concentrations showed two peaks; one coincided with the period of low progesterone synthesis and delayed embryonic development, whereas the second peak coincided with regressing corpus luteum. This finding suggests that increased serum melatonin level during November-December may be responsible for delayed embryonic development by suppressing progesterone synthesis. The study showed increased melatonin receptors (MTNR1A and MTNR1B) in the corpus luteum and in the utero-embryonic unit during the period of delayed embryonic development. The in vitro study showed that a high dose of melatonin suppressed progesterone synthesis, whereas a lower dose of melatonin increased progesterone synthesis by the ovary. The effects of melatonin on ovarian steroidogenesis are mediated through changes in the expression of peripheral-type benzodiazepine receptor, $\mathbf{P 4 5 0}$ side chain cleavage enzyme, and $\mathrm{LH}$ receptor proteins. This study further showed a suppressive impact of melatonin on the progesterone receptor (PGR) in the utero-embryonic unit; this effect might contribute to delayed embryonic development in $C$. sphinx. The results of the present study thus suggest that a high circulating melatonin level has a dual contribution in retarding embryonic development in $C$. sphinx by impairing progesterone synthesis as well as by inhibiting progesterone action by reducing expression of PGR in the utero-embryonic unit.

Reproduction (2009) 138 935-944
\end{abstract}

\section{Introduction}

Postimplantation delay (or retardation) in development is the least common form of embryonic delay and is observed only in the order Chiroptera (Krishna 1999). This was first reported in the phyllostomid bat, Macrotus californicus (Bradshaw 1962). Later, Bleier (1975) showed 8 months long gestation period of $M$. californicus, of which 4.5 months was of very slow embryonic growth. Delayed development has also been described in Artibeus jamaicensis (Flemming 1971) and was subsequently shown to occur in several other species of bats (Bernerd \& Meester 1982, Krishna \& Dominic 1982, 1983, Heideman 1989, Rasweiler \& Badwaik 1997, Heideman \& Powell 1998). Although delayed development has now been described in many bat species, the cause and control of delayed development have not yet been extensively investigated.

The mechanism and cause(s) of delayed embryonic development are under detailed investigations in the short-nosed fruit bat, Cynopterus sphinx (Meenakumari \& Krishna 2005, Banerjee et al. 2007, Meenakumari et al. 2009). The bat breeds twice a year in quick succession at Varanasi, India (Krishna \& Dominic 1983). This species exhibits delayed embryonic development during the first (winter) pregnancy (October-March). The developmental delay (or arrest) occurs at the gastrula stage of the embryo in C. sphinx during November and December (Meenakumari \& Krishna 2005). On the contrary, during the second (summer) pregnancy (AprilJuly), no embryonic delay is noted in April, which corresponds to the gastrula stage of development. The developmental process proceeds relatively faster during the second pregnancy than during the first pregnancy (Meenakumari \& Krishna 2005). A recent study on C. sphinx showed significantly lower concentrations of circulating progesterone and $17 \beta$-estradiol $\left(E_{2}\right)$ during the period of delayed development (Meenakumari et al. 2009). The cause of low progesterone synthesis during the period of delayed development in NovemberDecember needs further investigation.

Involvement of melatonin in the embryonic diapause has previously been described in carnivores (Mead 1993). Exogenous melatonin treatment was highly effective in lengthening the duration of the preimplantation 
period in mink and spotted skunk (May \& Mead 1986). Although the role of melatonin in bat reproduction is well demonstrated (Singh \& Krishna 1995, Abhilasha \& Krishna 1999), its role in delayed embryonic development has not yet been studied.

The objective of the present study, therefore, was first to determine the annual variation in the circulating melatonin level and correlate it with the serum progesterone level during different months of the two pregnancies; secondly to evaluate the role of melatonin on ovarian steroidogenic activity in vivo and in vitro; and thirdly to demonstrate whether melatonin directly acts at the utero-embryonic unit thus controlling delayed embryonic development in C. sphinx.

\section{Results}

\section{In vivo study}

Circulating level of melatonin and its correlation with serum progesterone level

The circulating melatonin level of $C$. sphinx varied significantly $(P<0.01)$ during different calendar months (Fig. 1a). The serum melatonin levels increased gradually from October to attain a highest concentration during November-December, coinciding with the period of delayed embryonic development. Melatonin levels then declined significantly $(P<0.01)$ during January and attained the lowest level in February-April. Circulating melatonin level rose again during May to attain a second peak in June, which coincided with regressing corpus luteum in the ovary. Melatonin levels remained high in July.

Changes in circulating progesterone (Fig. 1a) in C. sphinx have been described earlier in detail (Meenakumari et al. 2009). Serum melatonin level correlated with the circulating progesterone level differently during the two pregnancies. The serum melatonin level showed significant negative correlation $(r=-0.93)$ with circulating progesterone level during the first pregnancy from November to March, but positively $(r=0.95)$ from April to July.

\section{Circadian changes in circulating melatonin level}

Circadian changes in circulating melatonin level in $C$. sphinx showed nocturnal cycle with a significantly $(P<0.01)$ low point found in the middle of the day and a high point at late night (Fig. 1b).

\section{Changes in the melatonin receptors $1 \mathrm{a}$ and $1 \mathrm{~b}$ in the ovary during early embryonic development during the two pregnancies}

Immunoblot analysis of MTNR1A and MTNR1B in ovary Immunoblot analysis of melatonin receptor 1a (MTNR1A) in the ovary showed a single band between 35 and $40 \mathrm{kDa}$
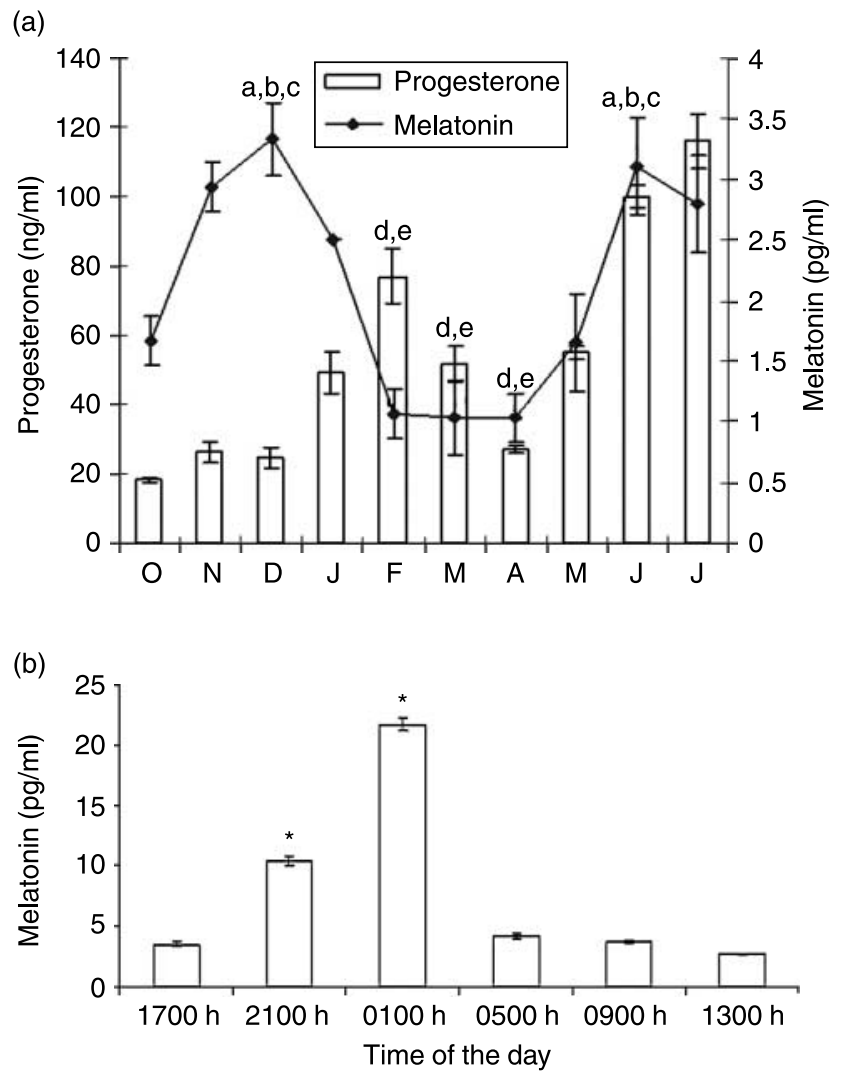

Figure 1 (a) Monthly changes in the circulating melatonin and progesterone concentration of $C$. sphinx. Values are given as the mean \pm S.E.M. and showed significant variation $(P<0.01)$ by ANOVA. In case of serum melatonin, values are significantly different by Duncan's test as compared with a, February; b, March; c, April; d, June, and e, December. (b) Circadian changes in circulating melatonin level in C. sphinx. Circulating melatonin level showed significant $(P<0.01)$ circadian variation. Each point represents the mean \pm S.E.M. for four animals. *Values are significantly high during dark/night phase as compared to light/day phase.

(Fig. 2a), which precisely corresponds to the predicted molecular mass of the receptor. There was greater expression of MTNR1A protein in the ovary during delayed phase than in the early phase of second pregnancy.

Immunoblot analysis of melatonin receptor $1 \mathrm{~b}$ (MTNR1B) in the ovary showed a major band approximately between 40 and $45 \mathrm{kDa}$ (Fig. 2c). There exists a significant $(P<0.01)$ difference in the expression of the 40-45 kDa band of MTNR1B in the ovary between delayed and normal gastrula phases of both the pregnancies, being high during delay. Both the receptors of melatonin showed a similar pattern of expression during the delayed embryonic development phase in NovemberDecember and in normal gastrula phase in April.

\section{Immunohistochemistry}

Immunohistochemical localization was performed in ovary for MTNR1B only. Localization of MTNR1B in the ovary during the early stage of two successive 
(a)

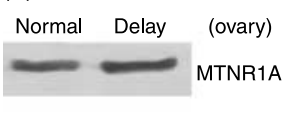

(b)

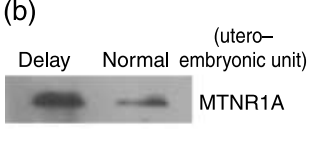

(c)

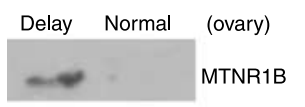

(d)

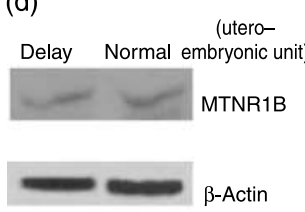

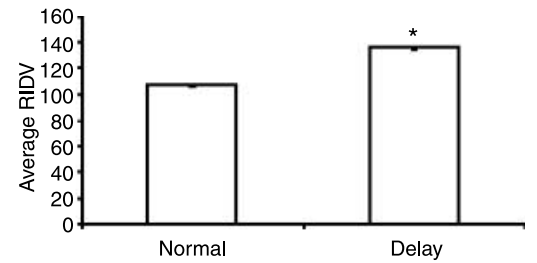
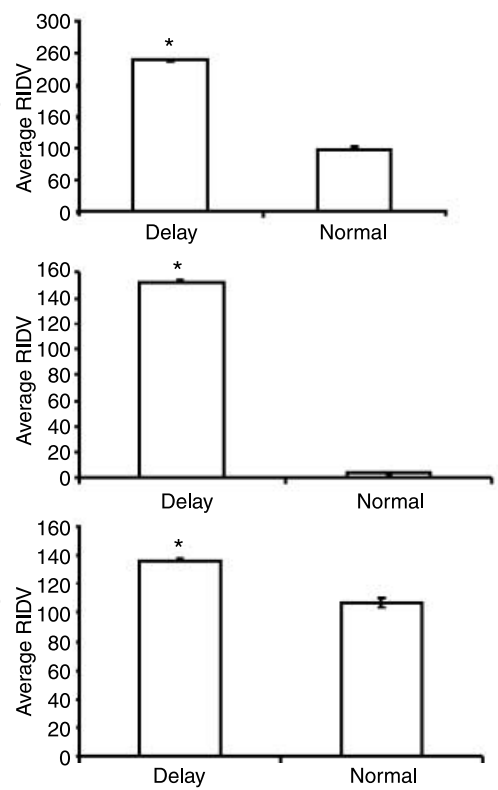

Figure 2 (a) Immunoblot analysis of melatonin receptor 1a (MTNR1A) protein in the ovary of $C$. sphinx during the early phase of the two pregnancies. Immunoblot analysis of MTNR1A in the ovary showed a major band between 35 and $40 \mathrm{kDa}$. Values are mean \pm S.E.M. Delay value $\left.{ }^{*}\right)$ is significantly different $(P<0.01)$ from normal. (b) Immunoblot analysis of MTNR1A protein in the utero-embryonic unit of $C$. sphinx during the early phase of the two pregnancies. Immunoblot analysis of MTNR1A in the ovary showed a major band between 35 and $40 \mathrm{kDa}$. Values are mean \pm s.E.M. Delay value $(*)$ is significantly different $(P<0.01)$ from normal. (c) Immunoblot analysis of melatonin receptor 1b (MTNR1B) protein in the ovary of $C$. sphinx during the early phase of the two pregnancies. Immunoblot analysis of MTNR1B in the ovary showed a major band approximately between 40 and $45 \mathrm{kDa}$. Values are mean \pm S.E.M. Delay value $\left({ }^{*}\right)$ is significantly different $(P<0.01)$ from normal. (d) Immunoblot analysis of MTNR1B protein in the utero-embryonic unit of $C$. sphinx during the early phase of the two pregnancies. Immunoblot analysis of MTNR1B in the utero-embryonic showed a major band approximately between 40 and $45 \mathrm{kDa}$. Values are mean \pm s.E.M. Delay value $\left(^{*}\right)$ is significantly different $(P<0.01)$ from normal.

pregnancies is shown in the Fig. 3. Relatively intense immunostatining was observed mainly in the corpus luteum during the period of delayed embryonic development in November-December. The immunostaining for MTNR1B was very mild in the corpus luteum of second pregnancy in April. The MTNR1B protein in corpus luteum was located in the cytoplasm along with plasma membrane.
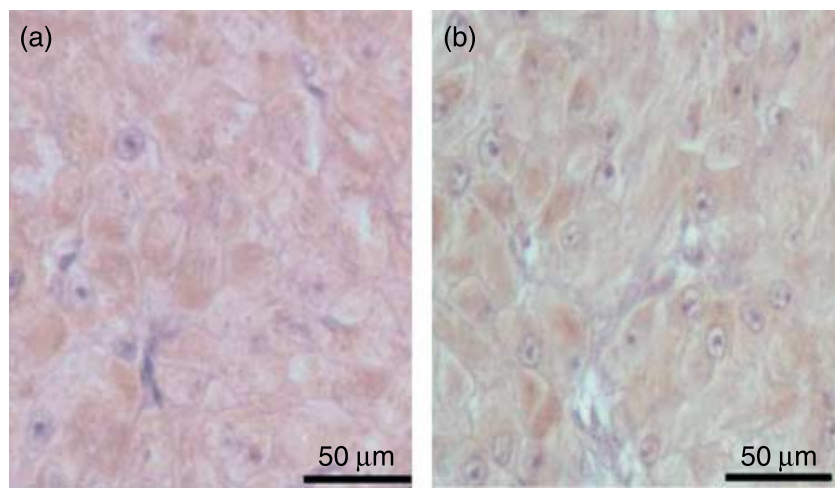

Figure 3 Immunolocalization of MTNR1B in the corpus luteum of C. sphinx during November-December (a) and April (b). Relatively intense immunostatining was observed mainly in the corpus luteum during the period of delayed embryonic development in NovemberDecember. The immunostaining for MTNR1B was very mild in the corpus luteum of second pregnancy in April. The MTNR1B protein in corpus luteum was located in the cytoplasm along with plasma membrane.

\section{Immunoblot analyses of melatonin receptors} (MTNR1A and B) and progesterone receptor in the utero-embryonic unit during the early stage of development of both the pregnancies of $\mathrm{C}$. sphinx

Immunoblot analyses of MTNR1A showed a single immunoreactive band between 35 and $40 \mathrm{kDa}$ (Fig. 2b). There was greater $(P<0.01)$ expression of MTNR1A protein in the utero-embryonic unit during delayed phase than in the early phase of second pregnancy.

Immunoblot analyses of MTNR1B in the uteroembryonic unit (Fig. 2d) revealed a major immunoreactive band approximately between 40 and $45 \mathrm{kDa}$ respectively. Two other nonspecific immunoreactive bands were also approximately obtained between 29 and $40 \mathrm{kDa}$ respectively. There was significant variation in the intensity of the major band approximately between 40 and $45 \mathrm{kDa}$ in the utero-embryonic unit between
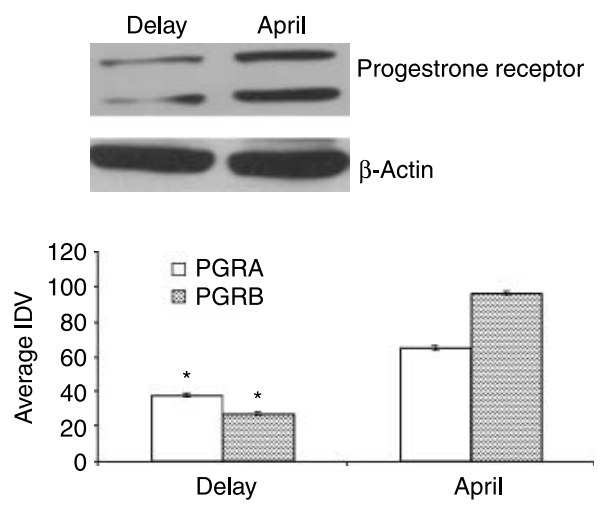

Figure 4 Immunoblot analysis of progesterone receptor (PGR) protein in the utero-embryonic unit of $C$. sphinx during the early phase of the two pregnancies. Immunoblot analysis of progesterone receptor in the utero-embryonic unit showed two immunoreactive bands at $\sim 85 \mathrm{kDa}$ (PGRA) and $\sim 120 \mathrm{kDa}$ (PGRB). Values are mean \pm s.E.M. Delay value $(*)$ is significantly different $(P<0.01)$ from normal. 


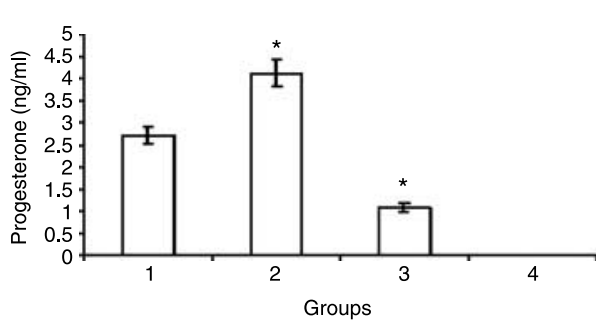

Figure 5 Effect of low $(100 \mathrm{ng} / \mathrm{ml})$ and high $(1 \mu \mathrm{g} / \mathrm{ml})$ doses of melatonin on progesterone production by the ovaries of $C$. sphinx in vitro. Values $(n=3)$ are mean \pm S.E.M. *Values are significantly $(P<0.01)$ different versus control.

delayed and normal phase, being higher during the delayed period.

Immunoblot analyses of progesterone receptor (PGR) in the utero-embryonic unit of $C$. sphinx showed two immunoreactive bands at $\sim 85 \mathrm{kDa}$ (PGRA) and $\sim 120 \mathrm{kDa}$ (PGRB; Fig. 4). Densitometric analysis of the immunoblot of PGR during the early phase (gastrula stage) of development of the two successive pregnancies showed significantly $(P<0.01)$ lower intensity during the period of delayed embryonic development in NovemberDecember in the utero-embryonic unit of $C$. sphinx.

\section{In vitro study}

Effects of melatonin on ovarian steroidogenesis and expression of peripheral-type benzodiazepine receptor, $P 450$ side chain cleavage enzyme, and $\mathrm{LH}$ receptors in vitro study

The effects of low and high doses of melatonin on ovarian progesterone synthesis in vitro by $C$. sphinx
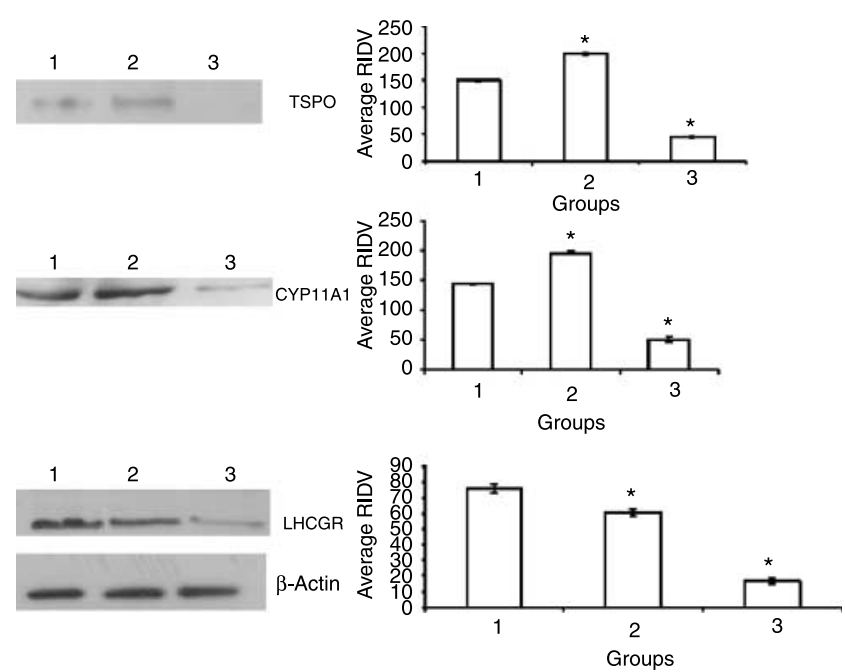

Figure 6 Immunoblot analyses of TSPO, CYP11A1, and LHCGR proteins in the ovaries of $C$. sphinx treated in vitro with melatonin. The different lanes in the above-mentioned blots represent: (1) control, (2) low dose melatonin $(100 \mathrm{ng} / \mathrm{ml})$, and (3) high dose melatonin $(1 \mu \mathrm{g} / \mathrm{ml})$. Values $(n=3)$ are mean \pm s.E.M. *Values are significantly $(P<0.01)$ different versus control.

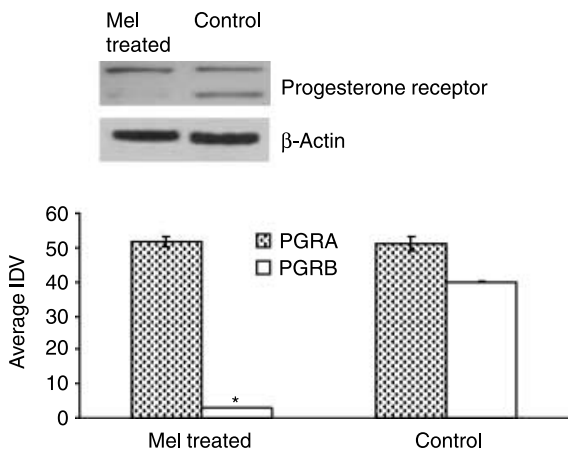

Figure 7 Immunoblot analyses of progesterone receptor protein in the utero-embryonic unit of $C$. sphinx treated in vitro with high dose $(1 \mu \mathrm{g} / \mathrm{ml})$ melatonin. Melatonin treatment to C. sphinx uteroembryonic unit in vitro during early pregnancy in NovemberDecember caused significant decline in the PGRB subunit of progesterone receptor in the utero-embryonic unit as compared to its expression in the control group. Values $(n=5)$ are mean \pm S.E.M. ${ }^{*}$ Values are significantly $(P<0.01)$ different versus control.

ovaries are shown in Fig. 5. The low dose of melatonin significantly enhanced progesterone synthesis, but the higher dose of melatonin significantly suppressed the progesterone synthesis in vitro by the ovaries.

Similarly, the low dose of melatonin significantly enhanced $(P<0.01)$ the ovarian expression of peripheraltype benzodiazepine receptor (TSPO), P450 side chain cleavage enzyme (CYP11A1), and LH receptor (LHCGR) proteins, whereas the high dose significantly suppressed $(P<0.01)$ the expression of TSPO, CYP11A1, and LHCGR proteins in the ovaries of C. sphinx (Fig. 6).

Effects of melatonin treatment on the expression of PGR in the utero-embryonic unit in vitro study

Melatonin treatment in vitro of the utero-embryonic unit of C. sphinx during early pregnancy in November caused significant decline in the expression of PGRB subunit of PGR as compared with its expression in the utero-embryonic unit of the control group (Fig. 7).

\section{Discussion}

The results of the present study showed significant variation in the circulating melatonin levels during two successive pregnancies in $C$. sphinx. Circulating melatonin concentration showed two peaks during the breeding cycle of $C$. sphinx. The first peak of circulating melatonin concentration during November-December coincided with the period of delayed embryonic development in C. sphinx. This period of high melatonin also coincided with the period of low progesterone synthesis by the corpus luteum in $C$. sphinx. The second peak of serum melatonin level in June coincided with the regressing corpus luteum during the second pregnancy (Meenakumari et al. 2009). The two periods of nadirs in circulating melatonin concentration closely coincided 
with the two periods of ovarian recrudescence and preovulatory follicular development in C. sphinx. These observations suggest that in C. sphinx, ovarian activity declines during the period of increased melatonin concentration. Thus, the present study suggests antigonadotropic action of melatonin in C. sphinx as demonstrated in several mammals (Reiter 1980).

Circadian changes in circulating melatonin level in C. sphinx showed nocturnal cycle with the low point found in the middle of the day, and the high point at late night. This is consistent with the findings demonstrated in mammals (McConnell \& Hinds 1985, Gündüz 2002). A recent study suggests that the switch that governs the action of melatonin is usually set at dawn and dusk, regardless of the maximum concentration reached by melatonin during the night (Lincoln et al. 2003). Circulating melatonin level assay in this study from the serum collected during evening hours (between 1600 and 1900), thus may be physiological relevant. Melatonin concentration during night from $C$. sphinx has recently been demonstrated by Haldar et al. (2006). The values of melatonin though reported by Haldar et al. (2006) are much higher than the values described in the present study, though both demonstrated similar trend in the seasonal variation in serum melatonin level in C. sphinx. Seasonal variation in serum melatonin level noted in the present study is not caused by the shift in the time of dusk, as killing of bat adjusted with the shift in the timing of the dusk.

It has recently been well demonstrated that low circulating progesterone may be responsible for the delayed embryonic development in C. sphinx (Meenakumari et al. 2009). The majority of the bat species showing delayed embryonic development in which serum progesterone levels have been investigated also showed low levels of serum progesterone during the period of delayed embryonic development as compared to the period of normal embryogenesis (Krishna 1999). M. californicus showed low levels of plasma progesterone during the period of delayed development, and its level increased significantly on resumption of normal embryonic development (Crichton et al. 1990). The studies on Miniopterus schrebersii showed low circulating progesterone level during delayed implantation (van der Merwe \& van Aarde 1989, Bernard et al. 1991). Progesterone levels are lowered during developmental delay in spotted skunk, Mephitis mephitis (Wade-Smith et al. 1980). Significant negative correlation between circulating melatonin and progesterone concentrations during the first pregnancy suggests that increased melatonin level during the delayed embryonic development may be responsible for suppressed progesterone synthesis in C. sphinx. This finding thus suggests that increased melatonin level during November-December may be responsible for delayed embryonic development by suppressing progesterone synthesis.
Previous studies showing involvement of melatonin in embryonic diapause have been described in carnivores (Mead 1989, 1993) and marsupials (McConnell \& Hinds 1985, Oates et al. 2004). Melatonin treatment was highly effective in lengthening the duration of the preimplantation period in mink and spotted skunk (Duby et al. 1972, May \& Mead 1986), while melatonin administration in marsupials terminates diapauses (Hinds \& den Ottolander 1983, McConnell \& TyndaleBiscoe 1985). In mink and spotted skunk, melatonin blocks implantation by suppressing prolactin (PRL) release (Berria et al. 1989, Kaplan et al. 1991). Unfortunately, circulating PRL could not be assayed in C. sphinx. Two species of marsupials, the tammar wallaby (Macropus eugenii) and Bennett's Wallaby (Macropus rufogriseus rufogriseus), exhibit embryonic diapauses after the winter solstice, when the corpus luteum and embryo remain in quiescence inspite of the presence of a pouch young (Curlewis et al. 1987). Contrary to the mink and spotted skunk, treatment with exogenous melatonin during seasonal quiescence results in termination of diapauses in both the wallaby (Hinds \& den Ottolander 1983, McConnell \& Tyndale-Biscoe 1985). Bilateral removal of the superior cervical ganglion in female tammars eliminates seasonal embryonic diapause (Renfree et al. 1981).

Melatonin may regulate progesterone synthesis by acting in one or a variety of organs such as the gonad (Abhilasha \& Krishna 1999), pituitary (Martin \& Saltler 1979), hypothalamus (Glass \& Lynch 1981, Malpaux et al. 2001), and CN (Glass \& Lynch 1982). Most studies investigating the mechanism by which melatonin regulates reproduction have been focused in the hypothalamus and pituitary as target tissues (Malpaux et al. 2001) with little attention directed to the role of melatonin in the ovary itself.

In the present study, both immunohistochemistry (IHC) and immunoblot analysis revealed the presence of MTNR1A and MTNR1B mainly in the corpus luteum of the ovary during pregnancy. This is consistent with the earlier reports on human and rat demonstrating the presence of MTNR1A and MTNR1B in granulosa cells and luteal cells (Soares et al. 2003). The presence of high levels of melatonin in follicular fluid in human and binding sites in the ovary (Brzezinski et al. 1987, Ronnberg et al. 1990, Niles et al. 1999) and, now, the presence of MTNR1A and MTNR1B in ovary suggest that melatonin directly acts as a modulator of ovarian functions.

Immunoblot analysis of MTNR1B antibody revealed a major band at about $40-45 \mathrm{kDa}$. This is similar to Xenopus tectal cells, which showed the expression of a glycosylated monomer at $45 \mathrm{kDa}$, although a dimeric form of $85 \mathrm{kDa}$ was also reported in these cells (Prada et al. 2005). The cloned MTNR1B (Reppert et al. 1995) has a predicted molecular weight of $40 \mathrm{kDa}$, not including posttranslational modification, which is similar to that reported for the deglycosylated receptor 
(38 kDa; Prada et al. 2005) suggesting that the bands in the present study, which were found between 40 and $45 \mathrm{kDa}$, correspond to MTNR1B. The present IHC study further demonstrated that MTNR1B protein in corpus luteum is located in the cytoplasm together with plasma membrane. This is in agreement with earlier study suggesting that the melatonin receptors in membrane and cytosolic ovarian fractions mediate distinct functions (Cohen et al. 1978).

Interestingly, two different doses of melatonin caused different effects on ovarian progesterone synthesis in vitro of C. sphinx. A low dose of melatonin caused stimulatory, whereas a high dose caused inhibitory effects on ovarian progesterone synthesis in vitro. This finding thus supports the earlier concept that melatonin is an essential mediator of seasonal reproduction and should not be considered as either an anti- or a pro- gonadotropic factor, although under given circumstances it can have either effect (Reiter 1993). This dose-dependent effect suggests direct (primary) action of melatonin on progesterone synthesis in the ovary of $C$. sphinx. This effect could not simply be 'zeitgeber' changes. This confirmed our in vivo study showing that decreased progesterone concentration coincided with increased melatonin level during the period of delayed embryonic development in November-December, whereas increased progesterone concentration coincided with decrease melatonin level during the normal embryonic development. Similar differential response of ovary to melatonin was demonstrated earlier in Scotophilus heathi (Abhilasha \& Krishna 1999). Earlier studies showed both stimulatory and inhibitory effects of melatonin on ovarian steroidogenesis in vitro during different phases of the reproductive cycle (Abhilasha \& Krishna 1999). Melatonin inhibited $\mathrm{LH}$-induced testosterone and progesterone synthesis by the ovary of $S$. heathi during winter dormancy and preovulatory phase. Whether increased melatonin level suppresses progesterone synthesis by inhibiting $\mathrm{LH}$ is not known. Although exogenous LH treatment in C. sphinx during the period of delayed development failed to increase the progesterone circulation (Meenakumari 2004). Batmanabane \& Ramesh (1996) showed that melatonin along with hCG significantly increased the $E_{2}$ synthesis during recrudescence, an effect that may suggest its role in initiating the breeding season, as shown in sheep (Karsch et al. 1984). The present study thus suggests that variation in circulating melatonin is a key factor responsible for the changes in the circulating progesterone level in C. sphinx, which in turn affects the rate of embryonic development. The effects of melatonin in the corpus luteum in vitro are intriguing. It would be interesting to find out whether treatment with melatonin inhibitor would increase progesterone synthesis during delayed embryonic development.

Little is known about the molecular events that mediate the effect of melatonin on ovarian steroidogenesis. Our previous investigation showed a direct effect of melatonin on steroidogenic enzymes such as $17 \beta$-hydroxysteroid dehydrogenase (Singh \& Krishna 1995). The effects of melatonin on steroidogenic enzymes have been shown in rat ( $\mathrm{Ng} \&$ Lo 1988, Mandal et al. 1990), and it appears that melatonin may have different effects on different steroidogenic enzymes. Our present study on C. sphinx suggests that the effect of melatonin on ovarian steroidogenesis is mediated by changes in the expression of TSPO, CYP11A1, and LHCGR proteins. The study showed marked variation in the expression of TSPO, CYP11A1, and LHCGR proteins in the ovary in response to different doses of melatonin treatment. Expression of TSPO, CYP11A1, and LHCGR decreases in response to treatment with higher dose of melatonin, whereas their expression decreased in response to lower dose. These findings thus suggest that high circulating concentration of melatonin during November-December may be responsible for suppressing progesterone level by decreasing expression of TSPO, CYP11A1, and LHCGR in the ovary of C. sphinx. This in turn may be responsible for the delayed embryonic development. It is possible that melatonin may be involved in maintaining a critical level of steroidogenic enzymes and LHCGR expression for ovarian function.

Since in an earlier study, treatment with progesterone failed to increase the rate of embryonic development in C. sphinx during the delayed period (Meenakumari \& Krishna 2005), an attempt was also made to find out whether melatonin suppressed progesterone action by acting directly at the utero-embryonic unit through its receptor. This study showed the presence of melatonin receptor in the utero-embryonic unit, and its level was significantly higher during the delayed phase than in April. Expression of MTNR1B receptor in the uteroembryonic unit of bat is consistent with the earlier study showing MTNR1A and MTNR1B mRNA in human placenta during first trimester (Iwasaki et al. 2005) and human choriocarcinoma (JEG-2) cell lines (Lanoix et al. 2006). Our study further showed significant decline in PGR of utero-embryonic unit treated with melatonin in vitro.

In brief, our results suggest an association between increased serum melatonin level and decrease in serum progesterone level and delayed embryonic development during November-December in C. sphinx. This study also showed the increased concentration of melatonin receptors (MTNR1A and B) in the corpus luteum, which coincided with increased circulating melatonin level during November-December. This increased effects of melatonin on corpus luteum caused suppressed progesterone synthesis. This suppressive effect of melatonin on progesterone synthesis was found to be mediated through decreased expression of TSPO, CYP11A1, and LHCGR proteins in the ovary. This study further demonstrated the increased concentration of both the 
melatonin receptors (MTNR1A and MTNR1B) in the utero-embryonic unit during November-December, and melatonin treatment or increased melatonin level during this period caused decreased expression of PGR protein. These findings thus suggest that increased melatonin level during November-December suppressed progesterone synthesis in the corpus luteum as well as suppressing the effect of progesterone on uteroembryonic unit thereby causing delayed embryonic development in C. sphinx.

\section{Materials and Methods}

All experiments were conducted in accordance with the principles and procedures approved by Banaras Hindu University, Departmental Research Committee. The female bats (C. sphinx) utilized in this study were captured alive from Ramnagar, Varanasi $\left(25^{\circ} \mathrm{N}, 83^{\circ} \mathrm{E}\right)$, India, from October to July, 2005-2008. Bats were then transported to the laboratory immediately. Body weight of bats was recorded as soon as they were brought to the laboratory (within $2 \mathrm{~h}$ of capture). Females weighing $43 \mathrm{~g}$ or more and having wingspan exceeding $46 \mathrm{~cm}$ were sexually mature (Krishna \& Dominic 1983). Pregnant female bats $(n=30)$ were euthanized between 1600 and $1900 \mathrm{~h}$ with an overdose of ether in a glass jar. To check daily changes in peripheral melatonin level, killing was done in the month of December at an interval of $4 \mathrm{~h}$ in a 24-h cycle. Night killing was done in dim red light. Blood serum collected was saved and stored at $-20^{\circ} \mathrm{C}$ until assayed for melatonin (seasonal and diurnal) and progesterone. Uteroembryonic unit of pregnant females in November-December (delayed gastrula phase) and in April (normal gastrula phase) was dissected out and kept at $-20^{\circ} \mathrm{C}$ for immunoblot analysis. One side of the ovary of each bat was dissected out, cleaned, and fixed in Bouin's fixative for $24 \mathrm{~h}$ at room temperature, dehydrated in ethanol, cleared in xylene, embedded in paraffin, and sectioned at $6 \mu \mathrm{m}$. The ovary of the other side of the female genital tract was stored at $-20{ }^{\circ} \mathrm{C}$ for immunoblot analysis.

\section{In vitro study}

\section{Effect of melatonin on ovarian steroidogenesis}

In order to study the direct effect of melatonin on ovarian steroidogenesis, the ovaries $(n=9)$ of $C$. sphinx were collected during delayed embryonic development in November-December. Effect of two doses of melatonin $(100 \mathrm{ng} / \mathrm{ml}$, low doses and $1 \mu \mathrm{g} / \mathrm{ml}$, high doses) treatment on in vitro ovarian steroidogenesis (progesterone secretion) and on ovarian expression of TSPO, CYP11A1, and LHCGR proteins was studied. Changes in progesterone synthesis and ovarian expression of TSPO, CYP11A1, and LHCGR proteins are taken as parameters to study the changes in ovarian steroidogenesis. Female C. sphinx were killed by decapitation as soon as they were brought to the laboratory. Their ovaries were quickly taken out and cleaned of any adhered fat tissue and oviduct in DMEM (Himedia, Mumbai, India) containing $250 \mathrm{U} / \mathrm{ml}$ penicillin and $250 \mu \mathrm{g} / \mathrm{ml}$ streptomycin sulfate. Ovaries were cultured by the method as described previously (Srivastava \& Krishna 2007) with some modifications. Culture medium was a mixture of DMEM (with sodium pyruvate and L-glutamine) and Ham's F-12 (1:1; v/v) Himedia) containing $100 \mathrm{U} / \mathrm{ml}$ penicillin, $100 \mu \mathrm{g} / \mathrm{ml}$ streptomycin, and $0.1 \%$ BSA (Sigma). After initial incubation for $2 \mathrm{~h}$ at $37^{\circ} \mathrm{C}$, culture medium was discarded, and ovaries (one per tube) were finally cultured in $1 \mathrm{ml}$ medium in a humidified atmosphere with $95 \%$ air and $5 \% \mathrm{CO}_{2}$ to maintain $\mathrm{pH} 7.4$ for $48 \mathrm{~h}$ at $37^{\circ} \mathrm{C}$ with two doses of melatonin: high dose $(1 \mu \mathrm{g} / \mathrm{ml})$ or low dose $(100 \mathrm{ng} / \mathrm{ml})$. Each treatment group was run in triplicate. Ovaries cultured under these conditions appear healthy and do not show any sign of necrosis. Ovaries were collected at the end of culture, washed several times with PBS, and kept frozen at $-20{ }^{\circ} \mathrm{C}$ for immunoblot study. Media was saved at $-20^{\circ} \mathrm{C}$ until assayed for progesterone.

\section{Effect of melatonin on utero-embryonic unit}

The utero-embryonic unit, the swollen part of the uterus during pregnancy, was dissected out from the bats during delayed embryonic development in November-December. The uteroembryonic unit containing the embryo in gastrula stage $(n=10)$ was immediately kept in medium DMEM (Himedia) containing $250 \mathrm{U} / \mathrm{ml}$ penicillin and $250 \mu \mathrm{g} / \mathrm{ml}$ streptomycin sulfate. Both the sides of the utero-embryonic unit were open, so that the culture media could freely pass across the entire unit during the in vitro culture. Then the entire unit was transferred to plastic culture dishes containing $1 \mathrm{ml}$ medium, which was a mixture of DMEM (with sodium pyruvate and L-glutamine) and Ham's F-12 $(1: 1 ; \mathrm{v} / \mathrm{v})$ (Himedia) containing $100 \mathrm{U} / \mathrm{ml}$ penicillin, $100 \mu \mathrm{g} / \mathrm{ml}$ streptomycin, and $0.1 \%$ BSA (Sigma). The utero-embryonic unit was divided between control and melatonin- $(1 \mu \mathrm{g} / \mathrm{ml})$ treated groups. The plastic culture dishes having the utero-embryonic unit in medium were maintained in a humidified atmosphere with $95 \%$ air and $5 \% \mathrm{CO}_{2}$ to maintain $\mathrm{pH} 7.4$ for $48 \mathrm{~h}$ at $37^{\circ} \mathrm{C}$. Control and treatment groups were run in triplicate. Uteroembryonic unit cultured under these conditions appears healthy and does not show any sign of necrosis. After $6 \mathrm{~h}$ of culture, the tissue was viable and there was no sign of necrosis cross checked with histology and trypan blue staining of the sections. Tissues were collected after $6 \mathrm{~h}$, washed several times with PBS, and kept frozen at $-20^{\circ} \mathrm{C}$ for immunoblot study.

\section{Validation of melatonin receptor (MTNR1A and MTNR1B) antibody}

MTNR1A antibody was purchased from Santa Cruz, Biotech (MTNR1A, R-18, Santa Cruz, CA, USA). A polyclonal antibody for MTNR1B directed against a 13 amino acid peptide (VKSEFKPRMQSDF), corresponding to a region of an intracellular loop of the Xenopus laevis MTNR1B receptor (Reppert et al. 1995), was generated in rabbits (Invitrogen).

Antibodies against melatonin receptor (MTNR1A and MTNR1B) were validated for the use in the bat ovary and uterus by immunoblotting. Immunoblot was performed by comparing MTNR1A and B immunoreactivity in the bat ovary and uterus with the immunostaining of these antibodies in the rat brain as positive control. Immunoblot analysis for MTNR1A in bat ovary and uterus showed a single band between 35 and $40 \mathrm{kDa}$, corresponding to a similar band obtained in rat brain. 
Immunoblot analysis for MTNR1B protein showed a single major band approximately between 40 and $45 \mathrm{kDa}$ in the bat ovary and uterus, the position of which corresponded to the band obtained in rat brain used as positive control. However, two very weak nonspecific bands were also approximately found between 29 and $40 \mathrm{kDa}$ in the uterus (data not shown).

\section{Immunohistochemistry}

Ovarian sections were processed through a standard protocol of IHC. After deparaffinization and rehydration, endogenous peroxidase was quenched with $0.3 \% \mathrm{H}_{2} \mathrm{O}_{2}$, equilibrated in $0.05 \mathrm{~mol} / \mathrm{l}$ Tris-Cl and $0.15 \mathrm{~mol} / \mathrm{l} \mathrm{NaCl}$ (Tris-buffered saline (TBS), pH 7.3). Background blocking was performed with normal horse serum. The tissue sections were incubated for $1 \mathrm{~h}$ at room temperature with rabbit polyclonal antibody against amphibian MTNR1B in TBS. The detection system used was $\mathrm{ABC}$ staining kit from Vector Laboratories, Novo Castra (UK). The peroxidase activity was revealed in $0.03 \% 3,3^{\prime}$-diaminobenzidine tetra-dihydrochloride (Sigma) in $0.01 \mathrm{M}$ Tris- $\mathrm{Cl}(\mathrm{pH}$ 7.6) and $0.1 \% \mathrm{H}_{2} \mathrm{O}_{2}$. Nucleus was counterstained with Elrich's hematoxylin. The negative controls were obtained by omitting the primary antibody and incubating the ovarian section with rabbit serum.

\section{Immunoblot}

The utero-embryonic unit and ovaries (three pooled) were homogenized to produce $10 \%$ homogenate. Furthermore, protein extractions and immunoblotting were performed as described previously (Srivastava \& Krishna 2007). Equal amount of proteins $(50 \mu \mathrm{g})$ as determined by Folin's method was loaded on to SDS-PAGE (10\%) for electrophoresis. Thereafter, proteins were transferred electrophoretically to nitrocellulose membranes (Sigma-Aldrich) overnight at $4{ }^{\circ} \mathrm{C}$. Nitrocellulose membranes were blocked for $60 \mathrm{~min}$ with TBS (Tris $50 \mathrm{mM}$ (pH 7.5) and $\mathrm{NaCl} 150 \mathrm{mM}$ ) containing 5\% fat-free dry milk and incubated with melatonin receptor antibodies (MTNR1A at a dilution of 1:200; and MTNR1B at a dilution of 1:250), rabbit anti-human TSPO antibody (1:500), rabbit antihuman CYP11A1 antibody (1:1000), and rabbit anti-human LHCGR antibody $(1: 1000)$ for $1 \mathrm{~h}$ at room temperature. Antibodies against LHCGR and P450 CYP11A1 enzyme were generously supplied by Craig S Atwood (William S Middleton Memorial Veterans Hospital, Madison, WI, USA) and Michael J Soares (Ralph L Smith Mental Retardation Research Center, University of Kansas, Kansas, USA) respectively. Membranes were then washed with three changes of TBS over $10 \mathrm{~min}$. Immunodetection was performed with anti-rabbit IgG-HRP conjugate $(1: 2000)$. Finally, blot was washed thrice with TBS and developed with ECL detection system (Bio-Rad). Similarly, a blot was developed for $\beta$-actin (Santa Cruz) at dilution 1:1000 as loading control. The densitometric analysis of the blots was performed by scanning and quantifying the bands for density value by using computer-assisted image analysis (Image $\mathrm{J} 1$, $38 \times, \mathrm{NIH}$, Bethesda, MD, USA). Experiments were repeated thrice with the same result. The densitometric data were presented as the mean of the integrated density value \pm S.E.M.

\section{$\boldsymbol{R I A}$}

\section{Melatonin RIA}

Circulating melatonin level was measured using RIA kit (Cat. \# RA608/100) purchased from DLD Diagnostika, Hamburg, Germany. The RIA kit was validated for melatonin measurement in C. sphinx. All the reagents were brought to room temperature before assay. Standards and bat serum samples $(100 \mu \mathrm{l})$ were added to the respective tubes. Then $25 \mu \mathrm{l}$ enzyme solution was added to all the tubes except the total count, mixed well, and centrifuged for $1 \mathrm{~min}$ at $500 \mathrm{~g}$. The tubes were then incubated for $1 \mathrm{~h}$ at room temperature $\left(\sim 20^{\circ} \mathrm{C}\right)$. Following incubation, $50 \mu \mathrm{l}$ assay buffer, $50 \mu \mathrm{l}^{125} \mathrm{I}$ tracer, and $50 \mu \mathrm{l}$ antiserum (rabbit anti-melatonin) were added to all the tubes (no antiserum in total and non specific binding (NSB)) in the sequence as described above with gentle mixing after each addition. All the tubes were centrifuged again at $500 \mathrm{~g}$ for $1 \mathrm{~min}$ and incubated at room temperature for $20 \mathrm{~h}$. After incubation, $500 \mu \mathrm{l}$ cold precipitating antiserum (goatanti-rabbit IgG in polyethylene glycol buffer) was added to all the tubes except total, and mixed thoroughly and incubated for 15 min at $4{ }^{\circ} \mathrm{C}$. Again all the tubes were centrifuged at $4{ }^{\circ} \mathrm{C}$ for $15 \mathrm{~min}$ at $3000 \mathrm{~g}$. Following centrifugation, supernatant was aspirated from each assay tube and the tubes were counted in a Beckman gamma counter. The coefficient of intra-assay variation $(\mathrm{CV})$ was $<5 \%$. The inter-assay $\mathrm{CV}$ of the melatonin kit was $<9.0 \%$. The kit was validated for use in C. sphinx. Blood serum sample from bats $(n=6)$ was pooled and serially diluted with assay buffer and treated against the standard curve. Dilution of bat serum ran parallel to the standard curve indicating the suitability and sensitivity of the assay in C. sphinx (data not shown).

\section{Progesterone assay}

Serum progesterone was assayed by RIA kit from ICN Biomedicals Inc., Costa Mesa, CA, USA. First, $25 \mu \mathrm{l}$ of each standard and sample were added to the anti-progesterone coated tubes. Progesterone ${ }^{125} \mathrm{I}(1 \mathrm{ml})$ was then added to each tube. The tubes were incubated at $37^{\circ} \mathrm{C}$ for $60 \mathrm{~min}$. After incubation, the tubes were decanted and empty tubes were checked in a gamma counter (Beckman, Geneva, Switzerland). The concentration of progesterone in the samples was deduced by extrapolation from the standard curve. All the tubes for progesterone were assayed together and intra-assay variation was $<10 \%$. Steroid assays for bat samples have been previously validated (Abhilasha \& Krishna 1996). Progesterone for the in vitro study was measured by using $100 \mu \mathrm{l}$ of the culture media and the same RIA kit.

\section{Statistical analysis}

Data are expressed as mean \pm S.E.M. The significance of the differences in melatonin and progesterone concentrations between groups was determined by one-way ANOVA followed by Duncan's multiple range test or a $t$-test. The data were considered significant if $P<0.01$. 


\section{Declaration of interest}

The authors declare that there is no conflict of interest that could be perceived as prejudicing the impartiality of the research reported.

\section{Funding}

This study was financially supported by the Department of Science and Technology, New Delhi.

\section{Acknowledgements}

Antibody against CYP11A1 enzyme was generously gifted by M J Soares (Ralph L Smith Mental Retardation Research Center, University of Kansas, KS, USA). A Banerjee highly acknowledges the financial assistance from the Centre of Advance Study, University Grant Commission, New Delhi.

\section{References}

Abhilasha S \& Krishna A 1996 High androgen production by ovarian thecal interstitial cells: a mechanism for delayed ovulation in a tropical vespertilionid bat, Scotophilus heathi. Journal of Reproduction and Fertility 106 207-211.

Abhilasha S \& Krishna A 1999 Ovarian steroidogenesis in the vespertilionid bat, Scotophilus heathi: role of melatonin. Acta Chiropterologica 1 223-230.

Banerjee A, Meenakumari KJ \& Krishna A 2007 Relationship between delayed embryonic development and metabolic factors and fat deposition in fruit bat Cynopterus sphinx. Reproduction, Fertility, and Development 19 626-633.

Batmanabane M \& Ramesh KG 1996 Effect of exogenous melatonin on the onset of puberty in female albino rats. Anatomical Record 245 519-524.

Bernard RT, Bojarski C \& Millar RP 1991 Plasma progesterone and luteinizing hormone concentrations and the role of the corpus luteum and LH gonadotrophs in the control of delayed implantation in Schreibers' long-fingered bat (Miniopterus schreibersii). Journal of Reproduction and Fertility 93 31-42.

Bernerd M \& Meester JAJ 1982 Female reproduction and the female reproductive cycle of Hipposideros caffer (Sundevall, 1846) in Natal, South Africa. Annals of the Transvaal Museum 33 131-144.

Berria M, Joseph MM \& Mead RA 1989 Role of prolactin and luteinizing hormone in regulating timing of implantation in the spotted skunk. Biology of Reproduction 40 232-238.

Bleier WJ 1975 Early embryology and implantation in the California leaf-nosed bat, Macrotus californicus. Anatomical Record 182 237-254.

Bradshaw GVR 1962 Reproductive cycle of the California leaf-nosed bat, Macrotus californicus. Mammalia 25 117-119.

Brzezinski A, Seibel MM, Lynch HJ, Deng MH \& Wurtman RJ 1987 Melatonin in human preovulatory follicular fluid. Journal of Clinical Endocrinology and Metabolism 64 865-867.

Cohen M, Roselle D, Chabner B, Schmidt TJ \& Lippman M 1978 Evidence for a cytoplasmic melatonin receptor. Nature 274 894-895.

Crichton EC, Hoyer PB \& Krutzsch PH 1990 Cellular composition and steroidogenic capacity of the ovary of Macrotus californicus (Chiroptera: Phyllostomatidae) during and after delayed embryonic development. Cell and Tissue Research 260 355-366.

Curlewis D, White AS \& Loudon ASI 1987 The onset of seasonal quiescence in the female Bennett's wallaby (Macropus rufogriseus rufogriseus). Journal of Reproduction and Fertility 80 119-124.

Duby RT, Pilbeam T \& Travis HF 1972 The influence of melatonin and hysterectomy on plasma progesterone levels of the mink (Mustela vison). Biology of Reproduction 758 (Abstract).

Flemming TH 1971 Artibeus jamaicensis delayed embryonic development in neotropical bat. Science 171 402-404.
Glass JD \& Lynch GR 1981 Melatonin: identification of sites of antigonadal action in mouse brain. Science 214 821-823.

Glass JD \& Lynch GR 1982 Evidence for a brain site of melatonin action in the white-footed mouse, Peromyscus leucopus. Neuroendocrinology 34 1-6.

Gündüz B 2002 Daily rhythm in serum melatonin and leptin levels in the Syrian hamster (Mesocricetus auratus). Comparative Biochemistry and Physiology. Part A, Molecular \& Integrative Physiology 132 393-401.

Haldar C, Yadav R \& Alipreeta R 2006 Annual reproductive synchronization in ovary and pineal gland function of female short-nosed fruit bat, Cynopterus sphinx. Comparative Biochemistry and Physiology. Part A 144 395-400.

Heideman PD 1989 Delayed development in Fischer's pygmy fruit bat, Haplonycteris fischeri, in the Philippines. Journal of Reproduction and Fertility 85 363-382.

Heideman PD \& Powell KS 1998 Age specific reproductive strategies and delayed embryonic development in an old world fruit bat, Ptenochirus jaogori. Journal of Mammalogy 79 295-311.

Hinds LA \& den Ottolander RC 1983 Effect of changing photoperiod on peripheral plasma prolactin and progesterone concentrations in the tammar wallaby (Macropus eugenii). Journal of Reproduction and Fertility 69 631-639.

Iwasaki S, Nakazawa K, Sakai J, Kometani K, Iwashita M, Yoshimura Y \& Maruyama T 2005 Melatonin as a local regulator of human placental function. Journal of Pineal Research 39 261-265.

Kaplan JB, Berria M \& Mead RA 1991 Prolactin levels in the western spotted skunk: changes during pre- and periimplantation and effects of melatonin and lesions to the anterior hypothalamus. Biology of Reproduction $\mathbf{4 4}$ 991-997.

Karsch FJ, Bittman EL, Foster DL, Goodman RL, Legan SJ \& Robinson JE 1994 Neuroendocrinal basis of seasonal reproduction. Recent Progress in Hormone Research 40 185-232.

Krishna A 1999 Reproductive delays in chiropterans. In Topics in Endocrinology and Reproduction, pp 410-421. Eds KP Joy et al. New Delhi, India: Narosa Publishing House.

Krishna A \& Dominic CJ 1982 Differential rates of fetal growth in two successive pregnancies in the emballonurid bat, Taphozous longimanus Hardwicke. Biology of Reproduction 27 351-353.

Krishna A \& Dominic CJ 1983 Reproduction in the female short-nosed fruit bat Cynopterus sphinx (Vahl). Periodicum Biologorum 85 23-30.

Lanoix D, Ouellette R \& Vaillancourt C 2006 Expression of melatoninergic receptors in human placental choriocarcinoma cell lines. Human Reproduction 21 1981-1989.

Lincoln GA, Andersson H \& Loudon A 2003 Clock genes in calendar cells as the basis of annual timekeeping in mammals - a unifying hypothesis. Journal of Endocrinology 179 1-13.

Malpaux B, Migaud M, Tricoire H \& Chemineau P 2001 Biology of mammalian photoperiodism and the critical role of the pineal gland and melatonin. Journal of Biological Rhythms 16 336-347.

Mandal H, Ghosh PK \& Biswas NM 1990 Effect of dihydrotestosterone on serum concentrations of alpha $2 \mu$-globulin and on spermatogenesis in melatonin-treated rats. Journal of Endocrinology 126 431-435.

Martin JE \& Saltler C 1979 Developmental loss of the acute inhibitory effect of melatonin on the in vitro pituitary luteinizing hormone and folliclestimulating hormone responses to luteinizing hormone-releasing hormone. Endocrinology 105 1007-1012.

May R \& Mead RA 1986 Evidence for pineal involvement in timing implantation in western spotted skunk. Journal of Pineal Research $31-8$.

McConnell SJ \& Hinds LA 1985 Effect of pinealectomy on plasma melatonin, prolactin and progesterone concentrations during seasonal reproductive quiescence in the tammar, Macropus eugenii. Journal of Reproduction and Fertility 75 433-440.

McConnell SJ \& Tyndale-Biscoe CH 1985 Response in peripheral plasma melatonin to photoperiod change and the effects of exogenous melatonin on seasonal quiescence in the tammar, Macropus eugenii. Journal of Reproduction and Fertility 73 529-538.

Mead RA 1989 The physiology and evolution of delayed iplantation in carnivores. In Carnivore Behaviour Ecology and Evolution, pp 437-464. Ed. JL Gittleman. New York: Cornell University Press.

Mead RA 1993 Embryonic diapause in vertebrates. Journal of Experimental Zoology 266 629-641. 
Meenakumari KJ 2004 Factors responsible for delayed embryonic development in the Indian fruit bat, Cynopterus sphinx. PhD Dissertation, Banaras Hindu University, India.

Meenakumari KJ \& Krishna A 2005 Delayed embryonic development in the Indian short-nosed fruit bat, Cynopterus sphinx. Zoology 108 131-140.

Meenakumari KJ, Banerjee A \& Krishna A 2009 Luteal cell steroidogenesis in relation to delayed embryonic development in the Indian short-nosed fruit bat, Cynopterus sphinx. Zoology 112 151-159.

Van der Merwe M \& Van Aarde RJ 1989 Plasma progesterone concentrations in the female natal clinging bat (Miniopterus schreibersii natalensis). Journal of Reproduction and Fertility 87 665-669.

Ng TB \& Lo LL 1988 Inhibitory actions of pineal indoles on steroidogenesis in isolated rat Leydig cells. Journal of Pineal Research 5 229-243.

Niles LP, Wang J, Shen L, Lobb DK \& Younlai EV 1999 Melatonin receptor mRNA expression in human granulosa cells. Molecular and Cellular Endocrinology 156 107-110.

Oates JE, Bradshaw FJ \& Bradshaw SD 2004 The influence of photoperiod on the reproductive activity of female Honey possums, Tarsipes rostratus (Marsupialia: Tarsipedidae): assessed by faecal progestagens and oestradiol-17 $\beta$. General and Comparative Endocrinology 139 103-112.

Prada C, Udin SB, Wiechmann AF \& Zhdanova V 2005 Stimulation of melatonin receptors decreases calcium levels in Xenopus tectal cells by

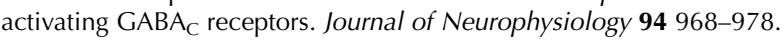

Rasweiler JJ \& Badwaik NK 1997 Delayed development in the short-tailed fruit bat, Carollia perspicillata. Journal of Reproduction and Fertility 109 7-20.

Reiter RJ 1980 The pineal and its hormones in the control of reproduction in mammals. Endocrine Reviews 1 109-131.

Reiter RJ 1993 The melatonin rhythm: both a clock and a calendar. Experientia 49 654-664.
Renfree MB, Lincoln DW, Almeida OFX \& Short RV 1981 Abolition of seasonal embryonic diapause in a wallaby by pineal denervation. Nature 293 138-139.

Reppert SM, Godson C, Mahle CD, Weaver DR, Slaugenhaupt SA \& Gusella JF 1995 Molecular characterization of a second melatonin receptor expressed in human retina and brain: the $\mathrm{Mel}_{1 \mathrm{~b}}$ melatonin receptor. PNAS $928734-8738$.

Ronnberg L, Kauppila A, Leppaluoto J, Martikainen H \& Vakkuri O 1990 Circadian and seasonal variation in human preovulatory follicular fluid melatonin concentration. Journal of Clinical Endocrinology and Metabolism 71 492-496.

Singh K \& Krishna A 1995 Inhibitory effects of melatonin on testosterone but not on androstenedione production during winter in the vespertilionid bat, Scotophilus heathi. Journal of Pineal Research 19 127-132.

Soares JM Jr, Masana MI, Ersahin C \& Dubocovich ML 2003 Functional melatonin receptors in rat ovaries at various stages of the estrous cycle. Journal of Pharmacology and Experimental Therapeutics 306 694-702.

Srivastava RK \& Krishna A 2007 Adiposity associated rise in leptin impairs ovarian activity during winter dormancy in Vespertilionid bat, Scotophilus heathi. Reproduction 133 165-176.

Wade-Smith J, Richmond ME, Mead RA \& Taylor M 1980 Hormonal and gestational evidence for delayed implantation in the striped skunk, Mephitis mephitis. General and Comparative Endocrinology 42 509-515.

Received 30 March 2009

First decision 12 May 2009

Revised manuscript received 3 July 2009

Accepted 18 August 2009 